\title{
Towards the development of a framework for the design of Automotive Infotainment Systems: First contextual approaches
}

\author{
Hacia el desarrollo de un framework para el diseño de Sistemas Infotainment \\ Automotrices: Primeras aproximaciones contextuales
}

\begin{abstract}
Carlos Alberto Domínguez-Báez ${ }^{1}$ (D), Ricardo Mendoza-Gonzalez ${ }^{1}$, Huizilopoztli Luna-García ${ }^{2}$ (D), Wilson J. Sarmiento ${ }^{3}$ (D), Mario Alberto Rodríguez-Díaz ${ }^{1}$, Francisco Luna-Rosas ${ }^{1}$ (D), Julio César Martínez-Romo ${ }^{1}$
\end{abstract}

\author{
${ }^{1}$ Instituto Tecnológico de Aguascalientes, Ags., Mexico \\ ${ }^{2}$ Universidad Autónoma de Zacatecas, Zacatecas, Zac., Mexico \\ ${ }^{3}$ Universidad Militar Nueva Granada, Bogotá, Colombia \\ albertodominguezmx1@gmail.com,mendozagric@mail.ita.mx,hlugar@uaz.edu.mx, \\ wilson.sarmiento@unimilitar.edu.co,mard812@hotmail.com,fjluna@ita.mx,jucemaro@yahoo.com
}

(Received: 21 September 2020; accepted: 3 November 2020; Published online: 1 December 2020)

\begin{abstract}
The objective of this article was to establish the first contextual approaches for the development of a framework focused on the design of automotive infotainment systems. Therefore, a method was developed to identify a group of characteristics of the infotainment system interfaces that ensure a good user experience by the user, according to previous studies. Besides, the establishment of usability is proposed as a basis for the development of the tool.
\end{abstract}

Keywords: Infotainment, User interfaces, User Experience, Framework.

Resumen. El objetivo de este artículo fue establecer las primeras aproximaciones contextuales para el desarrollo de un framework enfocado en el diseño de sistemas Infotainment automotrices. Por lo cual, se desarrolló un método para la identificación de un grupo de características de las interfaces de sistemas Infotainment que aseguren una buena experiencia de uso por parte del usuario, de acuerdo con estudios previos. Además, se plantea la usabilidad como base para el desarrollo de la herramienta.

Palabras clave: Infotainment, Interfaces de usuario, Experiencia de usuario, Framework.

Paper type: Research paper

\section{Introduction}

In general, a Framework is described as support structure in which a project can be organized and developed, composed of customizable and interchangeable components for development (Saavedra, 2009). In Software Engineering, a Framework is described as a generic structure that can be extended to create a more specific subsystem or application (Sommerville, 2005). It is also described as a skeleton with a collection of connection points that allow it to adapt to a specific problem (Pressman, 2006). In the context of Human-Computer Interaction, the Framework is defined as sets of tools that do not pretend to be a strict order in the invention and the interaction design process (Verplank, 2009). For this study, a Framework is defined as a conceptual structure that can serve as a basis for the design of interfaces in the automotive context.

Some of the advantages of using Frameworks are: First, the methodological rigor that guides the project development process. Second, by providing a foundation to guide the work process, they speed up development time. Third, they ensure transparency so that future work teams understand, evaluate and/or imitate the processes carried out with the Framework (Fach, 2001). The use of Frameworks also has some disadvantages, among which are mainly: Learning time. The time advantage gained by avoiding starting a project from scratch can be lost in learning to use the Framework. If not to be used for other projects. There is a high dependence on the results obtained concerning the Framework. Therefore, before starting to use the tool, the work teams must ensure that it is adequate for the results they want to obtain. Furthermore, each Framework is different, so it is not easy to switch between different Framework options (Wang et al., 
2018). Once the advantages and disadvantages have been defined, it is possible to establish that the use of Frameworks under the appropriate premises will greatly improve work teams' productivity.

Infotainment or infotainment systems are a collection of hardware and software elements installed in a vehicle that provides digital information systems and entertainment functionalities (Jorgensen, 2019). The most common applications include navigation, communication and connectivity, remote services, and telematics services.

The integration of these systems is becoming more common in automobiles. In principle, it is intended to provide satisfaction and comfort for both the driver and passengers. However, some reports show that greater efforts are still necessary to achieve this task. For example, in a study carried out on 60,000 vehicles, it was reported that only $56 \%$ of the owners are very satisfied with the Infotainment systems included in their vehicles, showing a large satisfaction gap between the model with the best satisfaction ratio (86\%) and the model with the worst ratio (46\%) (Consumer Reports, 2019). In addition, comparative studies have also been carried out between the Infotainment proposals of third parties and the developments of the automotive manufacturers themselves, reaching the conclusion that in terms of satisfaction, the latter are surpassed by Android Auto and CarPlay (Strayer et al., 2019). In addition to the above, there is evidence of the need for tools or alternatives that help work teams during the interface design process in the automotive context (Naujoks et al., 2019; Strayer et al., 2019; Varala \& Yammiyavar, 2018; Young et al., 2017).

The efforts to provide the design of automotive interfaces with specialized tools in the evaluation of various aspects are noteworthy about this need. For example, to evaluate safety and simplicity during the use of interfaces based on dialogues, Politis et al. (2018) interviewed a group of participants through questionnaires to obtain feedback on the use of Infotainment systems. To carry out the experiment, guidelines had to be developed, from which the prototypes were formed with those that the test subjects interacted with.

Similarly, another study related to the subject focused on comparing interfaces to determine which one is preferred by the user. During the experiment, 16 people participated who interacted with a simulator that allowed them to use a virtual car. The work team mentions the feasibility of developing design guidelines with the data collected (Walch et al., 2018). Likewise, it is important to mention the study developed to evaluate the vehicles' interiors' interfaces on the theoretical concept of complexity. The document indicates that to develop the experiment, it was necessary to carry out specialized guidelines to evaluate the object of the study (Lee \& Ji, 2019).

Previously, other reviews include the study of the desirable characteristics in an interface to guarantee a good user experience (Albers et al., 2020; Suh \& Ferris, 2019; Wang et al., 2010); however, they are carried out with emphasis on certain sections, such as size, distribution, or quantity of elements.

Derived from the above, it is possible to establish that there are currently tools and studies focused on evaluating user satisfaction during interaction with the interfaces of automotive Infotainment systems. However, the proposals aimed at developing specialized Frameworks in Automotive infotainment systems' design compared to other design alternatives are less frequent than other alternatives.

Therefore, to contribute to the repertoire of alternatives for designing interfaces, it is intended to contribute to the knowledge base and develop a Framework. As a first approach to this task, it was established to determine which characteristics users consider an interface should have to ensure a pleasant user experience during their interaction with it. Therefore, it was inferred convenient to carry out a study of the literature related to the analysis of user experience in automotive interfaces.

\section{Method for determining desirable characteristics of Infotainment interfaces}

During the literature review, it was established that there is a great diversity of concepts that collaborate with the user satisfaction experience while using Infotainment systems. However, it was observed that concepts such as intuitiveness, adaptability, and security, are common in various investigations. Thus, it was decided to establish the frequency in which said terms are mentioned as an indicator of their importance and impact on the user experience.

We opted to use the content analysis method to isolate characteristics mentioned in different studies and form a group or set of characteristics that would later be enriched by another group of characteristics suggested by the team. 
According to Berelson (1952), content analysis is a research technique that aims to be objective, systematic, and quantitative in studying the manifest content of the communication. Bardin (1996), for his part, describes him as a set of methodological instruments, applied to what he calls extremely diversified discourses.

This technique is recommended by Hernandez Sampieri et al. (2004) to study any type of communication objectively and systematically, and which consists of quantifying the messages or content in categories and subcategories and subjecting them to statistical analysis. Among its uses are: evaluating the degree of loading of some type of content from one or more television programs; study the appeals and characteristics of advertising campaigns in the mass media (radio, television, newspapers and magazines); compare propaganda strategies of political parties on the internet; know ideological discrepancies between various newspapers when dealing with a topic; determine the evolution of a certain class of patients who attend psychotherapy by analyzing their written and verbal expressions; collate vocabulary learned by children who are more exposed to computer use compared to children who use it less; know and contrast the position of various Latin American presidents regarding the problem of unemployment; compare styles of writers who are identified as part of the same literary trend; and/or analyze the quality and depth of the information present on the internet about a virus.

The reliability of this method is demonstrated by having been previously used in the research published by Guillaume \& Bath (2008), who studied the coverage and treatment given in the British press to information on vaccines for measles, mumps, and rubella over two months. Likewise, Hall \& Wright (2006) applied content analysis to examine judicial opinions. Even Christie \& Fleischer (2010) used this method to determine the designs and methods most used in evaluation studies published in scientific journals.

The purpose or objective must be clearly established; that is, what the analyst wants to know. Content analysis is carried out using coding, the process by which the relevant characteristics of a message's content are transformed into units that allow its precise description and analysis (Krippendorf, 1997).

To obtain the data from the analyzed studies, it was decided to define as the base of analysis a unit of grammatical basis, specifically the analysis of sentences and paragraphs. Consequently, the unit of analysis was a group of words mentioned or inferred from describing concepts deemed desirable by interface users, in general, those that referred to user satisfaction or experience in the context of automotive interfaces. The objective sections of the analysis mainly comprise:

1. Results.

2. Discussions and/or comments by the authors.

3. Conclusions.

Once the data extraction process was carried out, they were organized into tables to subsequently start an inference and comparison process in order to observe repeatability patterns of the words, see Figure 1.

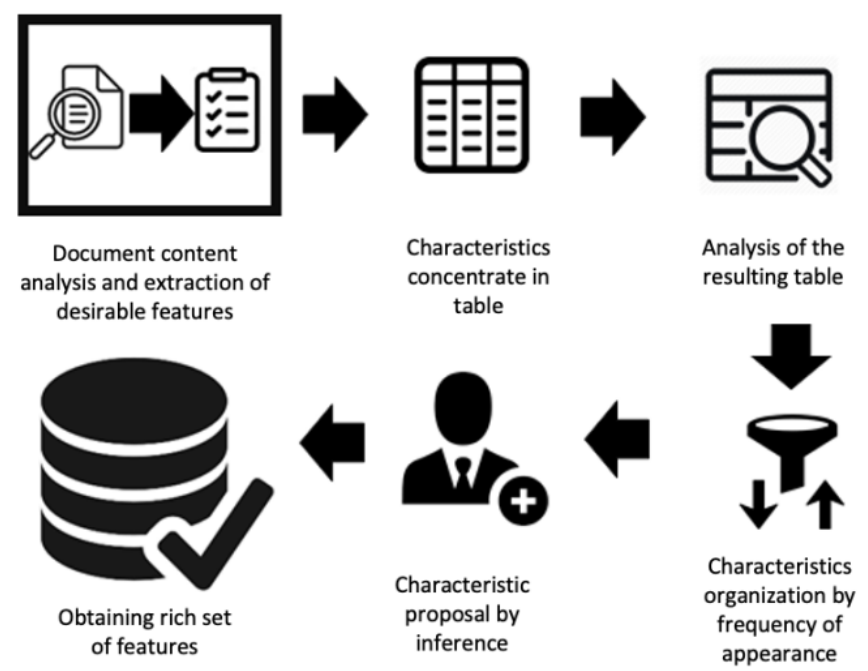

Figure 1. Diagram of the method for determining desirable characteristics of Infotainment interfaces 


\section{Results}

First, to carry out the content analysis, the objective was to locate user satisfaction or experience in the context of automotive interfaces. Subsequently, it was defined that the units would be composed of words that define the concepts that are concluded to be desirable by the users of the interfaces. In Table 1, they would include words such as Intuitive, Legible, Clear, Adjustable, Safe.

The search was carried out based on the aforementioned. A list of words was extracted from each publication analyzed. All the listings were ordered in a table for more orderly control of the information.

Once this table was obtained, patterns of the frequency of appearance of certain words could be observed. It is possible to observe that the "intuitive" characteristic that is underlined in Table 1 is repeated in three of the five studies in the example. However, other features such as "non-invasive" only appear once.

Table 1. Basic/essential characteristics of the interfaces according to various studies

\begin{tabular}{|c|c|c|c|c|}
\hline $\begin{array}{c}\text { (Blankenbach, } \\
\text { 2019) }\end{array}$ & $\begin{array}{l}\text { (Strayer et al., } \\
\text { 2019) }\end{array}$ & $\begin{array}{c}\text { (Varala \& } \\
\text { Yammiyavar, 2018) }\end{array}$ & (Politis et al., 2018) & (Lee \& Ji, 2019) \\
\hline Non-invasive & & Intuitive & Intuitive & Intuitive \\
\hline Readable & & Clear/simple & Clear/simple & Clear/simple \\
\hline $\begin{array}{l}\text { Adjustable/ } \\
\text { adaptable }\end{array}$ & $\begin{array}{l}\text { Adjustable/ } \\
\text { adaptable }\end{array}$ & $\begin{array}{l}\text { Adjustable/ } \\
\text { adaptable }\end{array}$ & Safe & Structured \\
\hline $\begin{array}{l}\text { Facilitator/ } \\
\text { proactive }\end{array}$ & & & $\begin{array}{l}\text { Facilitator/ } \\
\text { proactive }\end{array}$ & Consistent \\
\hline
\end{tabular}

Based on the data analysis, it was decided to order the characteristics into three groups (see Figure 2). The first two groups focused on the frequency of appearance and a third group that includes characteristics suggested by the work group.

High frequency of appearance characteristics. This group includes the characteristics that are frequently named in different investigations. There may be a relationship between this frequency of appearance and its importance for the user.

Low frequency of appearance characteristics. This group includes the characteristics that are unique to each study. These characteristics cannot be ruled out because the main objective of each investigation consulted is common. Its low rate of appearance may be related to less importance for the user. In the context of the Framework, these characteristics' priority will be low compared to that of the high frequency group.

Suggested features. They are characteristics inferred and/or proposed by the working group, based on the experience or results of other research related to interfaces, but not belonging to the automotive field. However, by belonging to the interface area, it is possible that they can contribute robustness to be taken into account in the context of the Framework. It is worth mentioning that it is possible that they were mentioned in automotive research that was not taken into account for the analysis base.

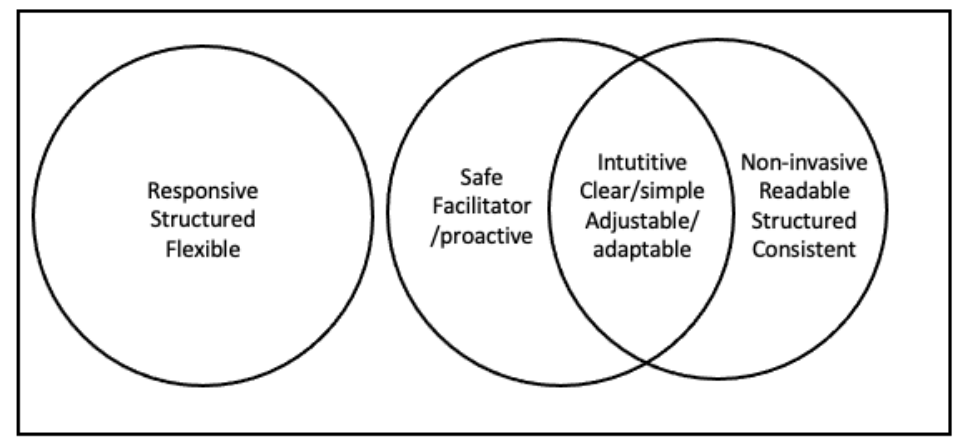

Figure 2. Representation of the enriched set made up of the group of specific, common and inferred characteristics. Method for determining desirable characteristics of Infotainment interfaces

As a result of the previous analysis, an enriched set conformed by the characteristics or needs that an interface should possess was obtained based on the data extracted from previously validated scientific 
investigations. It should be clarified that the set of features in Figure 2 can be further enriched by including a greater number of documents.

Based on a set of characteristics obtained through the previous methodology, strategies can be considered, and the best tools can be determined to ensure compliance with the complete list. The compilation of the final product complemented with optimal and specialized methodologies, concepts, and strategies for the context of automotive interfaces, guides development workgroups, and focuses on the resulting projects meeting high end-user satisfaction rates.

Since the objectives to be met have already been defined, and the Framework has been established as a tool to achieve this task, it is worth reflecting on which basis could adequately complement this tool. It is proposed to establish usability as a basis because, according to the Nielsen definition, it is responsible for ensuring that projects are clear, easy to use, intuitive, readable, reliable, and structured (Nielsen, 1994). This definition shares more than one characteristic with the group obtained during the analysis presented in this document and enriches the Framework by providing, for example, the aspect of reliability that had not been included in the analysis results. In addition to usability, it is possible to implement user-focused design philosophies, which allow us to know and understand their needs, limitations, behavior, and characteristics.

\section{Conclusions}

Based on an initial review of available works of alternatives for the design of automotive interfaces, it was established that Frameworks proposals in this context are found infrequently compared to other alternatives. Also, it has been verified that, under the appropriate premises, these tools greatly improve the productivity of work teams. Carrying out the determination of a group of characteristics identified above (see Figure 2) was necessary to establish a first contextual approach to developing the mentioned tool. For this reason, a method was developed to facilitate the identification of characteristics based on previous studies carried out in the context of automotive infotainment systems. The final result establishes a starting point for the development of further research on the point discussed and presents the guidelines to determine that it is relevant to carry out a new literature review, but systematically, in order to broaden the relevance, and provide a methodology that supports the results obtained so far.

\section{Statement of conflict of interest}

The authors declared no potential conflicts of interest with respect to the research, authorship and/or publication of this article.

\section{References}

Albers, D., Radlmayr, J., Loew, A., Hergeth, S., Naujoks, F., Keinath, A., \& Bengler, K. (2020). Usability EvaluationAdvances in Experimental Design in the Context of Automated Driving Human-Machine Interfaces. Information, 11(5), 240. https://doi.org/10.3390/info11050240

Bernard Berelson. (1952). Content Analysis in Communication Research . https://www.journals.uchicago.edu/doi/10.1086/617924

Blankenbach, K. (2019). Requirements and System Aspects of AR-Head-Up Displays. IEEE Consumer Electronics Magazine, 8(5), 62-67. https://doi.org/10.1109/MCE.2019.2923936

Christie, C. A., \& Fleischer, D. N. (2010). Insight Into Evaluation Practice: A Content Analysis of Designs and Methods Used in Evaluation Studies Published in North American Evaluation-Focused Journals. American Journal of Evaluation, 31(3), 326-346. https://doi.org/10.1177/1098214010369170

Consumer Reports. (2019). Built-In Systems CR members rate infotainment systems based on satisfaction with audio, calling, and navigation functions. https://article.images.consumerreports.org/prod/content/dam/CRO Images 2019/Magazine/06June/CRO-Inline-Built-In-Systems-Ratings-04-19

Fach, P. W. (2001). Design reuse through frameworks and patterns. IEEE Software, 18(5), 71-76. https://doi.org/10.1109/52.951498

Guillaume, L., \& Bath, P. A. (2008). A content analysis of mass media sources in relation to the MMR vaccine scare. 
Health Informatics Journal, 14(4), 323-334. https://doi.org/10.1177/1460458208096654

Hall, M. A., \& Wright, R. F. (2006, julio). Systematic Content Analysis of Judicial Opinions. 1st Annual Conference on Empirical Legal Studies Paper. https://papers.ssrn.com/abstract=913336.

Hernandez Sampieri, R., Fernández Collado, C., \& Pilar Baptista, L. (2004). Metodología de la investigación (J. M. Chacón (ed.); $\quad 5 \quad$ edition). https://www.esup.edu.pe/descargas/dep_investigacion/Metodologia

Jorgensen, C. (2019). The Developer Opportunity for Automotive Infotainment. Qualcomm develop network. https://developer.qualcomm.com/blog/developer-opportunity-automotive-infotainment

Krippendorf, K. (1997). Metodología de análisis de contenido. Paidos Comunicación.

Laurence, B. (1996). Análisis de contenido (2d Edition). AKAL S.A.

Lee, S. C., \& Ji, Y. G. (2019). Complexity of In-Vehicle Controllers and Their Effect on Task Performance. International Journal of Human-Computer Interaction, 35(1), 65-74. https://doi.org/10.1080/10447318.2018.1428263

Naujoks, F., Wiedemann, K., Schömig, N., Hergeth, S., \& Keinath, A. (2019). Towards guidelines and verification methods for automated vehicle HMIs. Transportation Research Part F: Traffic Psychology and Behaviour, 60, 121-136. https://doi.org/10.1016/j.trf.2018.10.012

Nielsen, J. (1994). Usability Engineering (1st Editio). Morgan Kaufmann.

Politis, I., Revell, K., Stanton, N., Langdon, P., Adebayo, D., Bradley, M., Clarkson, P. J., Skrypchuk, L., Mouzakitis, A., Eriksson, A., \& Brown, J. W. H. (2018). An Evaluation of Inclusive Dialogue-Based Interfaces for the Takeover of Control in Autonomous Cars. Proceedings of the 2018 Conference on Human Information Interaction\&Retrieval - IUI 18, 601-606. https://doi.org/10.1145/3172944.3172990

Pressman, R. S. (2006). Ingeniería del software: un enfoque práctico (6a ed.). The McGraw-Hill.

Saavedra, E. (2009). Grails: Framework para el desarrollo de aplicaciones Web. Revista de Software Libre ATIX, 3241.

Sommerville, I. (2005). Ingeniería del software. Pearson Educación.

Strayer, D. L., Cooper, J. M., McCarty, M. M., Getty, D. J., Wheatley, C. L., Motzkus, C. J., Goethe, R. M., Biondi, F., \& Horrey, W. J. (2019). Visual and Cognitive Demands of CarPlay, Android Auto, and Five Native Infotainment Systems. Human Factors: The Journal of the Human Factors and Ergonomics Society, 61(8), 1371-1386. https://doi.org/10.1177/0018720819836575

Suh, Y., \& Ferris, T. K. (2019). On-Road Evaluation of In-vehicle Interface Characteristics and Their Effects on Performance of Visual Detection on the Road and Manual Entry. Human Factors: The Journal of the Human Factors and Ergonomics Society, 61(1), 105-118. https://doi.org/10.1177/0018720818790841

Varala, V., \& Yammiyavar, P. (2018). Product Graphical User Interfaces: A Study for the Meaning and Usability on Automobile Dashboard User Interfaces in Indian Context. En Ergonomics in Caring for People (pp. 267-272). Springer Singapore. https://doi.org/10.1007/978-981-10-4980-4_33

$\begin{array}{lllll}\text { Verplank, (2009). } & \text { B. Interaction Design } & \text { Sketchbook. } & \text { https:/hci.rwth- }\end{array}$ aachen.de/index.php?option=com_attachments\&task=download\&id=797

Walch, M., Mühl, K., Baumann, M., \& Weber, M. (2018). Click or Hold. Extended Abstracts of the 2018 CHI Conference on Human Factors in Computing Systems, 1-6. https://doi.org/10.1145/3170427.3188614

Wang, Y., Mehler, B., Reimer, B., Lammers, V., D’Ambrosio, L. A., \& Coughlin, J. F. (2010). The validity of driving simulation for assessing differences between in-vehicle informational interfaces: A comparison with field testing. Ergonomics, 53(3), 404-420. https://doi.org/10.1080/00140130903464358

Wang, Z., Norris, S. L., \& Bero, L. (2018). The advantages and limitations of guideline adaptation frameworks. Implementation Science, 13(1), 72. https://doi.org/10.1186/s13012-018-0763-4

Young, K. L., Koppel, S., \& Charlton, J. L. (2017). Toward best practice in Human Machine Interface design for older drivers: A review of current design guidelines. Accident Analysis \& Prevention, 106, 460-467. https://doi.org/10.1016/j.aap.2016.06.010 